\title{
A Grid-Connected Photovoltaic Interface System for Delivering Active and Reactive Powers
}

\author{
Neilcy Tjahja Mooniarsih ${ }^{1}$, Syafrudin Masri ${ }^{2}$, Mohd. Hafeez ${ }^{3}$, Ayong Hiendro ${ }^{4}$ \\ ${ }^{1,4}$ Department of Electrical Engineering, Tanjungpura University, Pontianak, Indonesia \\ ${ }^{2,3}$ School of Electric and Electronic Engineering, Universiti Sains Malaysia (USM), Malaysia
}

\section{Article Info \\ Article history: \\ Revised Jul 3, 2018 \\ Keyword: \\ Grid-connected \\ Interface \\ Photovoltaic \\ Reactive power \\ Power factor}

Received Mar 9, 2018

Accepted Aug 6, 2018

\begin{abstract}
This paper presents a grid-connected photovoltaic (PV) interface for delivering both active and reactive powers. The PV interface employs $\mathrm{H}$ bridge topology DC-DC converter and inverter with analog control technology. The power flow is controlled solely by the adjustable DC output voltage of the DC to DC converter. In order to evaluate the PV interface system's performances, it is tested by delivering power to the grid with low pawer factor. The experimental results show that at $300 \mathrm{~W}$ active load, the inverter could deliver the reactive power of 400VAR. The PV interface could also produce very low harmonic voltage and current distorsions. The laboratory measurements show that the total harmonic distortions of inverter output voltage and current are $0.46 \%$ and $0.05 \%$, respectively.
\end{abstract}

Copyright $\odot 2018$ Institute of Advanced Engineering and Science. All rights reserved.

\section{Corresponding Author:}

Ayong Hiendro,

Departement of Electrical Engineering,

Tanjungpura University,

Jl. Jenderal Ahmad Yani, Pontianak, Kalimantan Barat, Indonesia.

Email: ayong.hiendro@ee.untan.ac.id

\section{INTRODUCTION}

As the rapid progress of power electronics technology, the photovoltaic (PV) energy is now wellknown as an important energy resource, because it is renewable, clean, abundant, and no pollution produced. The PV system becomes more interesting and the installed capacity has rapidly increased around the world [1].

The PV system could be operated in grid-connected and off-grid mode of operations. In a gridconnected PV system, the PV is commonly interfacing the grid through a voltage source inverter [2]. The major concerns of the PV interface are the efficiency and controllability, including the power quality [3], [4], when it is connected to the grid which not only absorbs active power, but also reactive power. The inverter of PV interface has to be able to operate in reactive power mode, instead of in active power mode [5]. Many control methods [6]-[9] have been investigated to deal with the problems in order to improve the PV interface's performances. However, the good PV interface needs very complex and relative expensive controller.

In this paper, an alternative simple and low cost grid-connected PV interface system is proposed to delivery both active and reactive powers. The whole control system is implemented using analog control technology. The interface treated here is designed on the basis of computer simulation and laboratory experiments are conducted to evaluate its performances. The PV interface is tested to deliver power to the grid with a low power factor. 


\section{RESEARCH METHOD}

The grid-connected PV interface system consists of PV array, interface, and grid as seen in Figure 1. The interface circuit consists of two sections: a DC to DC converter and an inverter. The DC to DC converter is used to convert the DC input voltage to a proper level of DC output voltage. The DC output voltage is then fed to the inverter. The inverter is used to convert the DC input voltage to AC output voltage at proper magnitude, frequency and phase angle, before it is interconnected with the utility grid.

The DC to DC converter employs an H-bridge topology and a high frequency ferrite transformer, as shown in Figure 2. The isolation is incorporated for to the flexibility and safety purpose. For the simplicity purpose, the two-level operation mode is applied. The DC output voltage must be set to a proper level so that the amount of power delivered is as expected. For a stand-alone PV system, a high DC voltage is a must for feeding the load via transformerless inverter and this leads to the need of a high step up DC to DC converter [10], [11].

A predetermined dead-time is applied to avoid overlapped operation of the switches of the same legs, which may lead to switches damage. The dead-time and a commutating capacitors are also needed to perform soft-switched operation of the switches. The pulses wide modulation controller is drived by a microcontroller so that the switches (i.e MOSFETS) are easily driven due to its chip's high current sourcing capability. The four switchers are driven separately and isolated each other by using auto-coupler pulse transformers. A PI-compensator is used to stabilize the DC output voltage. A tolerable overshoot occasionally occurs due to the output LC filter property.

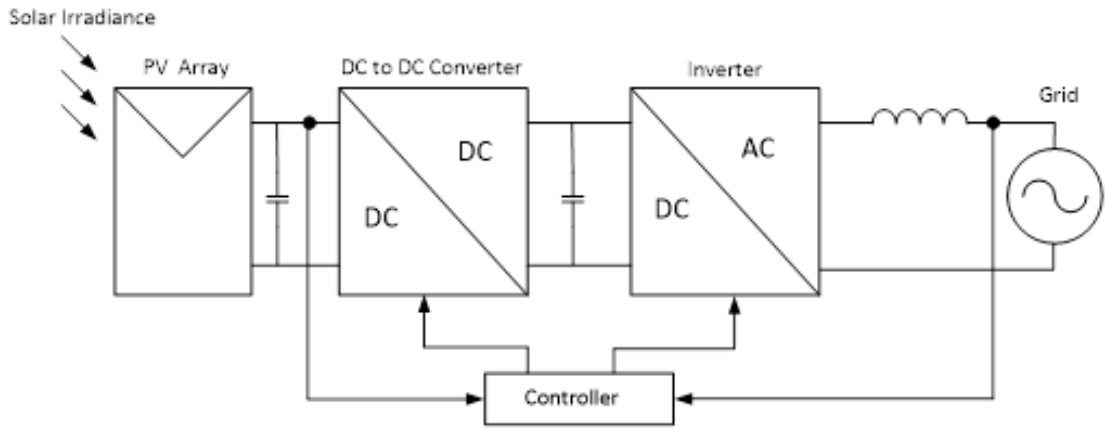

Figure 1. Configuration of grid-connected PV system

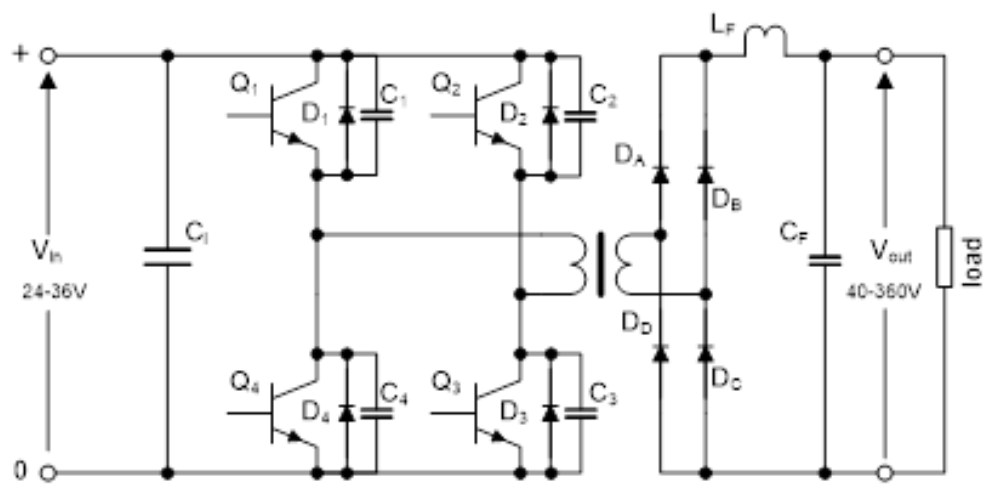

Figure 2. Proposed DC-DC converter

Referring to Figure 3, the operation principle of power delivering from the inverter to the grid can be explained as follows. The fundamental component of inverter output voltage can be written as $\left|V_{i n v}\right| \angle \delta$, while the grid voltage can be written as $\left|V_{\text {grid }}\right| \angle 0$. Then, AC current flowing from the inverter output to the grid is expressed by

$$
I=\frac{\left|V_{i n v}\right|}{\left|Z_{t}\right|} \angle(\delta-\gamma)-\frac{\left|V_{\text {grid }}\right|}{\left|Z_{t}\right|} \angle-\gamma
$$




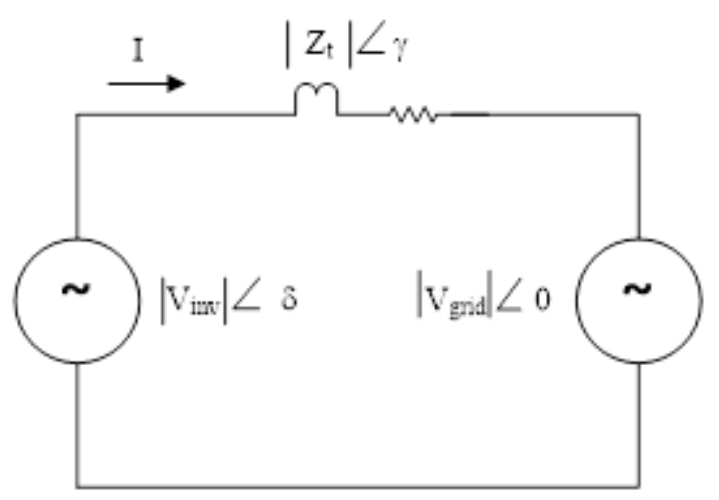

Figure 3. Interconnection of inverter to utility grid

The complex power delivered by the inverter is then given by

$S=\frac{\left|V_{\text {inv }}\right|^{2}}{\left|Z_{t}\right|} \cos \gamma-\frac{\left|V_{\text {inv }}\right|\left|V_{\text {grid }}\right|}{\left|Z_{t}\right|} \cos (\gamma+\delta)$

The active and reactive powers are

$$
\begin{aligned}
& P=\frac{\left|V_{\text {inv }}\right|^{2}}{\left|Z_{t}\right|} \cos \gamma-\frac{\left|V_{\text {inv }}\right|\left|V_{\text {grid }}\right|}{\left|Z_{t}\right|} \cos (\gamma+\delta) \\
& Q=\frac{\left|V_{\text {inv }}\right|^{2}}{\left|Z_{t}\right|} \sin \gamma-\frac{\left|V_{\text {inv }}\right| V_{\text {grid }} \mid}{\left|Z_{t}\right|} \sin (\gamma+\delta)
\end{aligned}
$$

The tie-line reactor could be assumed as a purely inductive or $\gamma=90^{\circ}$, and hence

$$
\begin{aligned}
& P=\frac{\left|V_{\text {inv }}\right|\left|V_{\text {grid }}\right|}{X_{t}} \sin \delta \\
& Q=\frac{\left|V_{\text {inv }}\right|^{2}}{X_{t}}-\frac{\left|V_{\text {inv }}\right| V_{\text {grid }} \mid}{X_{t}} \cos \delta
\end{aligned}
$$

In this work, the inverter output voltage $\left(V_{i n v}\right)$ is generated by an H-bridge topology as shown in Figure 4. The inverter is operated at three-level mode and sinewave modulation at fixed modulation index of 1.0 .

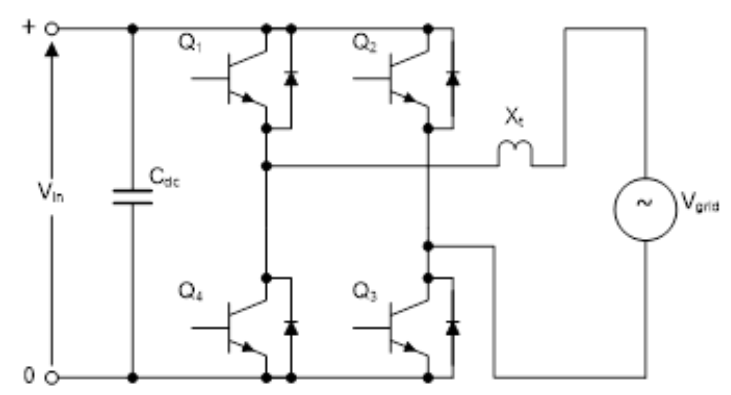

Figure 4. H-bridge inverter topology 
From (5) and (6), it is shown that the active and reactive powers delivered by the inverter are dependent to the inverter voltage and phase angle, while tie-line reactance and grid voltage are set as parameters. To achieve the maximum active power delivered, the phase angle must be set to $90^{\circ}$. At this angle, the inverter sends the reactive power at the value of $\left|V_{i n v}\right|^{2} / X_{t}$. Although the active and reactive power flow could be controlled by variating the phase angle $\delta$, this technique is not used due to the nonlinearity property of the function, as mentioned in (5) and (6). In this case, the power flow is controlled solely by the DC bus voltage. In this work, the phase shifting of $90^{\circ}$ is implemented by using a small-signal operational amplifier as seen in Figure 5.

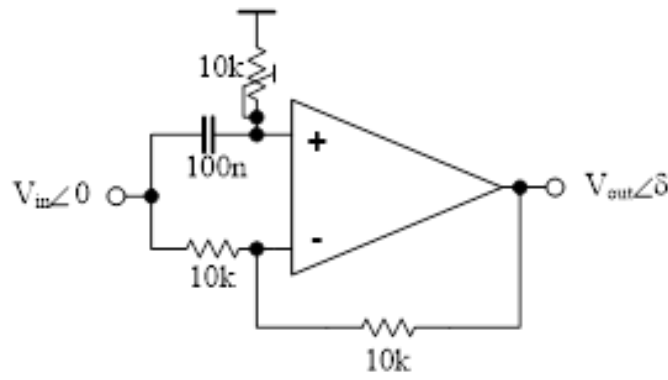

Figure 5. Phase shifter circuitry

Due to the dead-time effect, there is a possibility of the inverter to produce low-order harmonic voltage, which could be ommited. The voltage harmonics only give small effect on current harmonics due to the current filtering action of the tie-line reactor. This filtering effect also enables to use low frequency switching for the inverter. Low frequency switching implies low switching losses. The prototype is run by switching frequency of $1 \mathrm{kHz}$.

\section{RESULTS AND ANALYSIS}

In this section, computer simulations and laboratory experimentals are conducted to analyze the proposed grid-connected PV system's performances. The grid-connected PV circuit and the prototype are presented in Figures 6 and 7. The grid-connected PV system is designed to deliver 300W active power and $400 \mathrm{VAR}$ reactive power, and hence it is needed the 500VA rating of inverter.

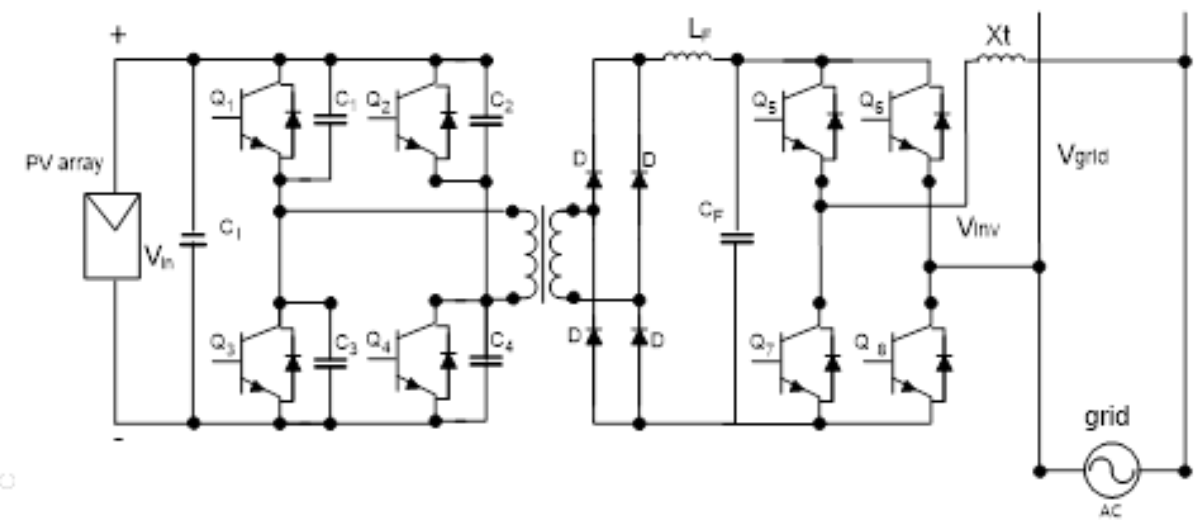

Figure 6. Grid-connected PV circuit

The circuit variables and parameters are: Vin $=36$ VDC, voltage ratio of transformer is Np:Ns = 9:108 with $\mathrm{Lm}=1.5 \mathrm{mH}$, inductor as interface between inverter and grid utility $\mathrm{LF}=1.0 \mathrm{mH}$. The capacitor $\mathrm{CF}=330 \square \mathrm{F}$, capacitors $\mathrm{C} 1, \mathrm{C} 2, \mathrm{C} 3, \mathrm{C} 4$ are $22 \mathrm{nF}$ and $\mathrm{Lt}=0.81 \mathrm{mH}$. The delay time of MOSFET- IRFP450 
is $\mathrm{td}=3.75 \square \mathrm{s}$ and switching frequency of switches is $\mathrm{fs}=16 \mathrm{kHz}$ with modulation index $\mathrm{m}=1.0$. The phase angle is set on $\delta=90 \mathrm{o}$, grid voltage Vgrid $=220 \mathrm{~V}$ and system frequency $\mathrm{f}=50 \mathrm{~Hz}$.

Simulation and experimental results show that the waveform of inverter output voltage, grid voltage and inverter output current as seen in Figures.8-10. It is proven that the phase shifter works perfectly and gives filtering effect as seen in Figure 11. Although the grid voltage is a few distorted, the shifted signal has a better waveform. The gate drivers use low-cost CMOS 4050s and 6N136 opto-isolators. The phase displacement of the inverter fundamental output voltage is advanced by 90o. The total harmonic distortion (THD) of inverter output voltage and current are $0.46 \%$ and $0.05 \%$, respectively. The total harmonic current distorsion is less than 5\%, and it is inside the limit as specified by IEC 61727 for utility interface [12].

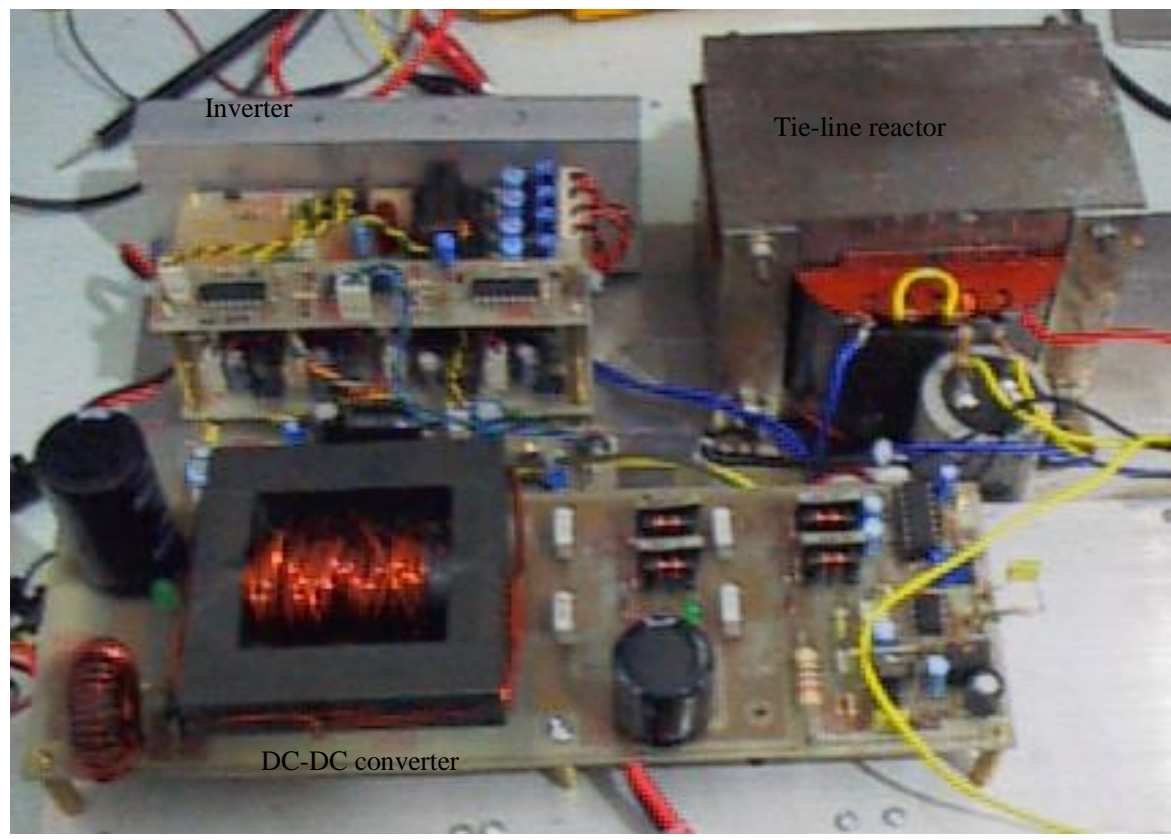

Figure 7. Prototype of grid-connected PV system interface

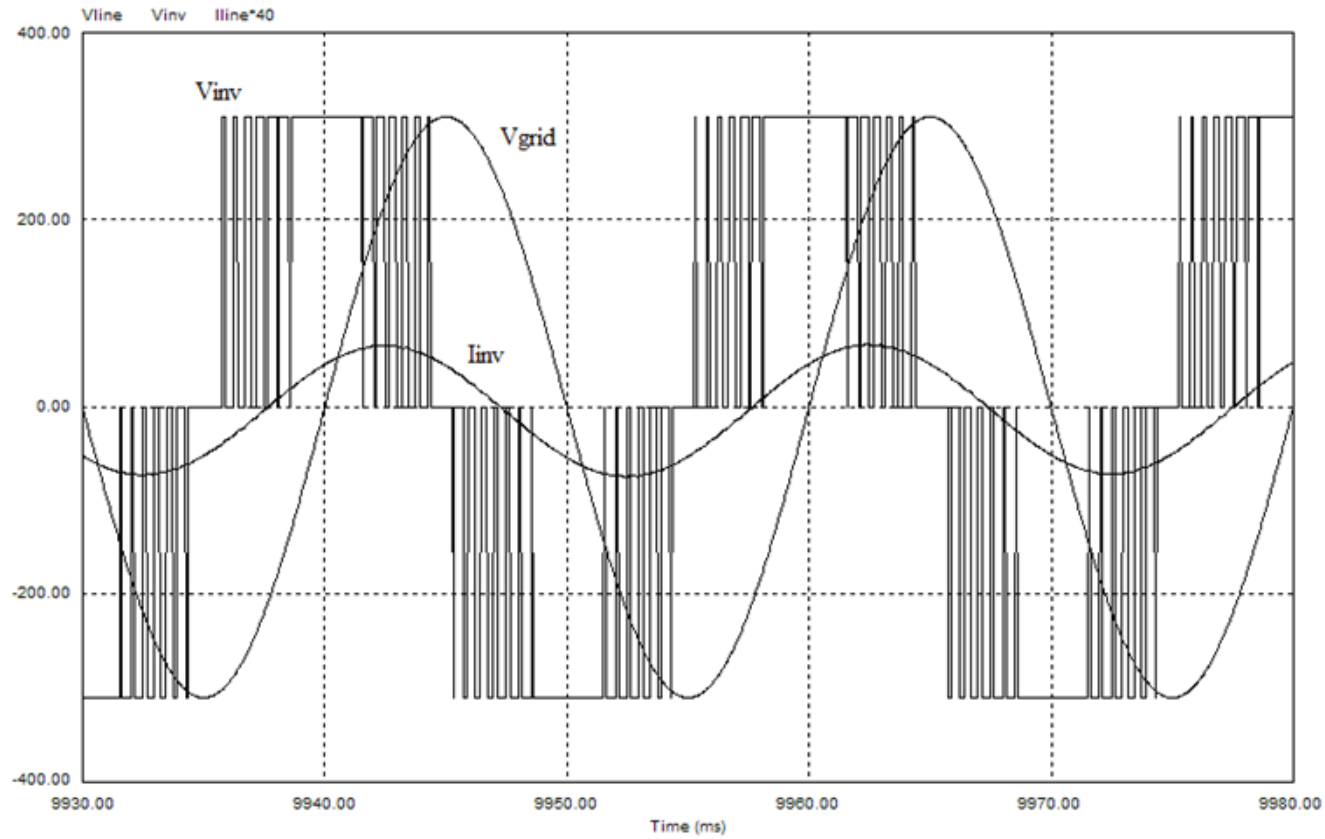

Figure 8. Inverter output voltage, grid voltages, and inverter output current 


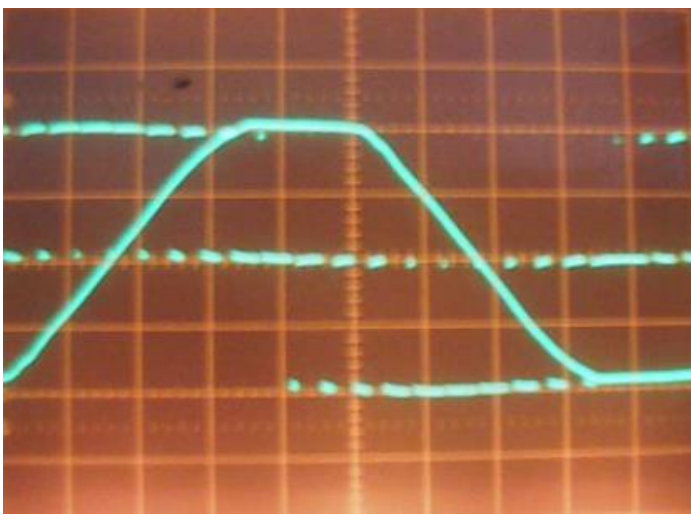

Figure 9. Inverter output voltage and grid voltage

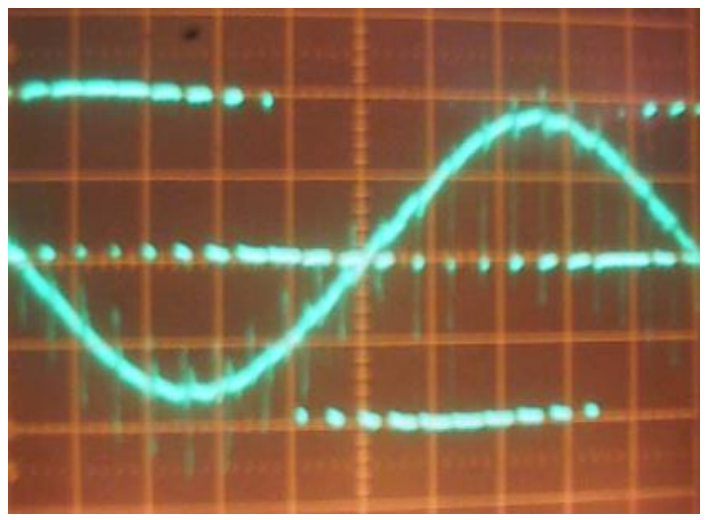

Figure 10. Inverter output voltage and current

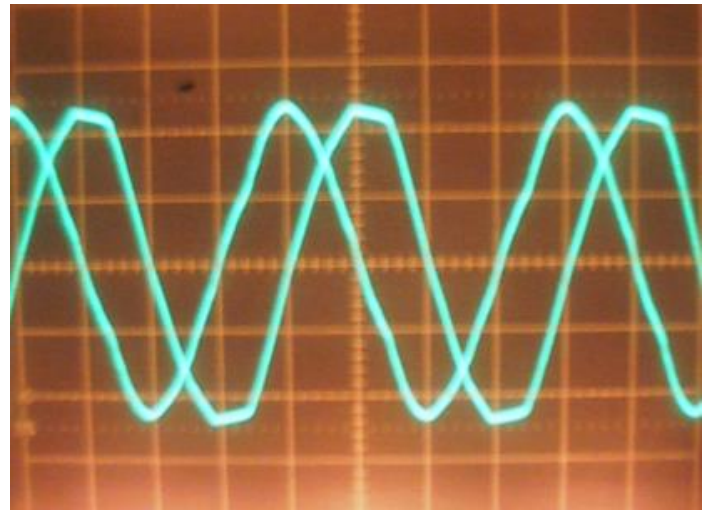

Figure 11. Attenuated grid voltage and its shifted waveform

From the experimental results, it is also found that at $300 \mathrm{~W}$ active load, the output inverter voltage Vinv is $325 \mathrm{~V}$ while grid voltage is $240 \mathrm{~V}$. At this condition, the inverter delivers the reactive power of $400 \mathrm{VAR}$. Hence, the apparent power sent by the inverter is 500VA. Increasing the reactive power delivered to the grid increases the apparent power but it does not have impact on the active power. However, the PV interface has to supply more apparent power if the grid needs larger reactive power.

\section{CONCLUSION}

A simple and low-cost grid-connected PV interface system has been disigned and tested in the laboratory. It has been proven that the PV interface has the capability to produce both active and reactive powers with low harmonic output voltage and current distorsions. The whole system is implemented using commercial standard components. For this system presented, the transmission of reactive power is inevitable. The filtering effect of the tie-line reactance enables to use low switching-frequency. This advantage implies to high efficiency for the inverter section.

\section{REFERENCES}

[1] R. Pinto, S. Mariano, M.R. Calado, J.F. De Souza, "Impact of Rural Grid-Connected Photovoltaic Generation Systems on Power Quality," Energies, vol. 9, pp. 739-753, 2016.

[2] F. Blaabjerg, Z. Chen, S. Kjaer, "Power Electronics as Efficient Interface in Dispersed Power Generation Systems," IEEE Trans. on Power Electronics, vol. 19, no.5, pp. 1184 - 1194, 2004

[3] G. Varshney, D.S. Chauhan, M.P. Dave," Evaluation of Power Quality Issues in Grid Connected PV Systems," International Journal of Electrical and Computer Engineering (IJECE), vol. 6, no. 4, pp. 1412-1420, 2016.

[4] M.K. Rathi, N.R. Prabha," Grid Interconnected Photo Voltaic System Using Shunt Active Filter for Power Quality Improvement," International Journal of Power Electronics and Drive System (IJPEDS), vol. 9, no. 1, pp.365-376, 2018. 
[5] A. Maknouninejad, N. Kutkut, I. Batarseh, Z. Qu, "Analysis and Control of PV Inverters Operating in VAR Mode at Night," in proceedings of 2011 IEEE PES Innovative Smart Grid Technologies (ISGT), 2011.

[6] N. Hamrouni, A. Chérif, "Modelling and Control of a Grid Connected Photovoltaic System," Revue des Energies Renouvelables, vol. 10, no. 3, pp. 335 - 344, 2007.

[7] H.M. El-Helw, M. Al-Hasheem, M.I. Marei, "Control Strategies for the DAB Based PV Interface System," PLOS One, vol. 11, no.8, pp. e0161856, 2016.

[8] V. Prasad, P.R. Jayasree, V. Sruthy, "Active Power Sharing and Reactive Power Compensation in a Gridtied Photovoltaic System", in proceeding of International Conference on Processing of Materials, Minerals and Energy, 2016.

[9] M.A. Jusoh, M.Z. Daud," Control Strategy of a Grid-connected Photovoltaic with Battery Energy Storage System for Hourly Power Dispatch," International Journal of Power Electronics and Drive Systems (IJPEDS), vol. 8, no.4, pp. 1830-1840, 2017.

[10] R. Arulmurugan, N.S. Vanitha, "Optimal Design of DC to DC Boost Converter with Closed Loop Control PID Mechanism for High Voltage Photovoltaic Application," International Journal of Power Electronics and Drive System (IJPEDS), vol. 2, no.4, pp. 434-444, 2012.

[11] V. S. Prasadarao K, K.V. Krishna Rao, P.B. Koteswara Rao, T. Abishai,” Power Quality Enhancement in Grid Connected PV Systems using High Step up DC-DC Converter," International Journal of Electrical and Computer Engineering (IJECE), vol. 7, no.2, pp. 720-728, 2017.

[12] IEC 61727, "Photovoltaic (PV) Systems - Characteristics of the Utility Interface," IEC, 2004 